\title{
Microstructure of Supported Cobalt Fischer-Tropsch Catalysts
}

\author{
O. Ducreux ${ }^{1 *}$, B. Rebours' ${ }^{2}$, J. Lynch' ${ }^{1}$, M. Roy-Auberger ${ }^{2}$ and D. Bazin ${ }^{3}$ \\ 1 Institut français du pétrole, IFP-Rueil, 1-4 avenue de Bois-Préau, 92852 Rueil-Malmaison - France \\ 2 Institut français du pétrole, IFP-Lyon, BP 3, 69390 Vernaison - France \\ 3 Laboratoire de Physique des Solides, Bât. 510, Université Paris XI, 91405 Orsay Cedex - France \\ e-mail: olivier.ducreux@axens.net - bernadette.rebours@ifp.fr - john.lynch@ifp.fr - magalie.roy@ifp.fr - bazin@lps.u-psud.fr \\ *Currently at Axens, 89 boulevard Franklin Roosevelt, 92508 Rueil-Malmaison, France
}

\begin{abstract}
Résumé - Microstructure de catalyseurs Fischer-Tropsch à base de cobalt supporté - La structure de particules métalliques de cobalt supporté sur silice ou sur alumine, et en présence ou non d'un promoteur $(\mathrm{Ru})$, a été étudiée in situ par diffraction des rayons $\mathrm{X}$ conventionnelle et anomale. Par comparaison avec des diagrammes simulés, il est montré que cette structure est caractérisée par la présence de défauts d'empilement dont la densité est directement reliée à la température de réduction du cobalt. Des traitements de carburation/décarburation sous $\mathrm{CO}$ et $\mathrm{H}_{2}$ nous ont permis de modifier de manière contrôlée la microstructure du cobalt métallique pour un même support tout en limitant la variation de la taille des particules. Quel que soit le support, et en présence ou non d'un promoteur, les basses températures de réduction favorisent la formation de la forme hexagonale compacte du cobalt, alors qu'une réduction à haute température favorisera la forme cubique faces centrées.

Dans les conditions de la synthèse Fischer-Tropsch, les catalyseurs contenant du cobalt à forte densité d'empilements de type hexagonal compact montrent une activité en conversion du CO nettement supérieure à celle des catalyseurs majoritairement cubiques.
\end{abstract}

\footnotetext{
Abstract - Microstructure of Supported Cobalt Fischer-Tropsch Catalysts - The structures of metallic cobalt particles supported on silica (with and without $R u$ promoter) and on alumina have been investigated in-situ by conventional and anomalous X-ray diffraction. Comparison with simulated XRD patterns shows the structure to consist of a defect phase characterised by the presence of stacking faults, the density of which is directly related to the temperature at which the cobalt oxide is reduced. Controlled modification of the cobalt microstructure, while maintaining the same support and promoter has been achieved with limited variation of the particle size, notably via $\mathrm{CO}-\mathrm{H}_{2}$ treatment leading to the formation and decomposition of cobalt carbide. Independently of the support or the presence of a promoter, low reduction temperatures increase the tendency to form hexagonal close packed (hcp) structure whilst at high reduction temperatures face centred cubic ( $f c c$ ) stacking is preferentially formed.

The catalytic activity for $\mathrm{CO}$ conversion in Fischer-Tropsch conditions is greatly increased for catalysts with a majority of hcp stacking compared to those containing predominantly fcc phase particles.
} 


\section{INTRODUCTION}

Among the industrial challenges for the near future, the production of hydrocarbons from synthesis gas $\left(\mathrm{H}_{2}, \mathrm{CO}\right)$ in the Fischer-Tropsch process is one of the most important $[1,2]$ as synthesis gas can be produced from a large variety of sources (natural gas, biomass, coal, etc.) and the process can be oriented towards a variety of products (fuels, paraffins, alcohols, etc.). The catalytic activity and selectivity of the frequently used Co based catalysts in $\mathrm{CO}$ hydrogenation have been shown to depend on several factors such as particle size, nature of the support [3-5], the presence of promoters [6-8] and pre-treatment conditions [9]. Modification of preparation parameters is known to strongly affect the microstructure of cobalt supported catalysts [10]. The microstructure of the metallic phase has been the subject of several studies by X-ray diffraction (XRD) as cobalt can exist in both hexagonal close packed (hcp) and face centred cubic (fcc) forms. However, perhaps because of the number of parameters that can be varied, it is difficult to extract from the literature a clear image of the specific effect of cobalt particle microstructure on FischerTropsch activity.

In-situ XRD studies of silica supported cobalt catalysts have given evidence that the fcc form is prevalent after reduction under hydrogen whilst the hcp form results from direct syngas $\left(\mathrm{CO}+\mathrm{H}_{2}\right)$ activation [11]. Studies on used catalysts after high pressure Fischer-Tropsch synthesis have found that fcc cobalt forms on silica supports whereas the hcp structure is detected on alumina supports [12]. Zirconia support was found to promote poorly crystalline hexagonal metallic cobalt [13]. In the latter study, it was proposed that amorphous cobalt or hcp cobalt with crystallographic defects are active phases in the Fischer-Tropsch reaction, while fcc crystallised cobalt has lower catalytic activity.

In nanometre scale particles both fcc and hcp forms may coexist $[14,15]$, possibly leading to an influence of the resulting stacking faults on the catalytic activity. For example, as underlined by S. Kala et al. [16], the presence of many stacking faults in nanoparticles results in large amounts of hydrogen incorporation.

In this paper, we investigate the microstructure of cobalt catalysts supported on silica (with and without $\mathrm{Ru}$ promoter) and on alumina via in-situ X-ray diffraction (XRD) experiments, including synchrotron based anomalous XRD. In order to eliminate as much as possible variables such as type of support or presence of a promoter, we have concentrated our study on post-synthesis modification of the microstructure of the metallic cobalt particles. The main aim of the present study is thus to elucidate the role in Fischer-Tropsch activity of the fcc and hcp phases, and of the presence of stacking faults. Careful extraction of the XRD signal due to the metallic phase and confirmation, through diffraction pattern simulation, of the presence of stacking faults in the nanometre scale particles were a pre-requisite to achieve this goal.

\section{EXPERIMENTAL}

\subsection{Catalyst Preparation}

Bulk $\mathrm{Co}_{3} \mathrm{O}_{4}$ purchased from Ultrex was used as a control sample for in-situ XRD. Catalyst samples were prepared via impregnation using a cobalt nitrate solution on amorphous silica, poorly crystallised gamma alumina and highly crystallised titanium oxide (Degussa P25). The Co content was measured by X-ray fluorescence and the surface area by BET (see Table 1).

TABLE 1

Characteristics of the catalysts studied

\begin{tabular}{c|c|c}
\hline Support & $\begin{array}{c}\text { Co content } \\
(\mathrm{wt} . \% \pm 0.03)\end{array}$ & $\begin{array}{c}\text { Surface area } \\
\left(\mathrm{m}^{2} / \mathrm{g}\right)\end{array}$ \\
\hline None (Commercial oxide) & 73.4 & 10 \\
\hline $\mathrm{SiO}_{2}$ & 13.0 & 460 \\
\hline $\mathrm{Al}_{2} \mathrm{O}_{3}$ & 13.3 & 180 \\
\hline $\mathrm{TiO}_{2}$ & 11.3 & 20 \\
\hline
\end{tabular}

Prior to analysis, all the catalysts were dried at $120^{\circ} \mathrm{C}$ and calcined under air at $400^{\circ} \mathrm{C}$ for $4 \mathrm{~h}$.

An additional ruthenium promoted catalyst, which we shall call Co- $\mathrm{Ru} / \mathrm{SiO}_{2}$, was prepared from a calcined $\mathrm{Co} / \mathrm{SiO}_{2}$ sample by impregnation with $\left(\mathrm{Ru}\left(\mathrm{NH}_{3}\right)_{6}\right) \mathrm{Cl}_{3}$ followed by drying at $110^{\circ} \mathrm{C}$ and calcination for $4 \mathrm{~h}$ at $300^{\circ} \mathrm{C}$. The $\mathrm{Ru}$ content was determined as $0.45 \mathrm{wt} . \%$.

The catalysts were characterised by temperature programmed reduction (TPR), carried out with a $5 \% \mathrm{H}_{2} / \mathrm{Ar}$ mixture at a gas flow rate of $30 \mathrm{~mL} / \mathrm{min}$ and a temperature ramp of $2^{\circ} \mathrm{C} / \mathrm{min}$.

\subsection{X-Ray Diffraction}

\subsubsection{Conventional X-Ray Diffraction}

Powder diffraction patterns were obtained using a Siemens D501 $\theta / 2 \theta$ diffractometer with a copper anode and a scintillation detector. Contributions other than $\mathrm{Cu} \mathrm{K \alpha}$, as well as secondary fluorescence from the cobalt, were eliminated using a graphite monochromator placed in the path of the diffracted beam.

\subsubsection{Anomalous X-Ray Diffraction}

Anomalous X-ray diffraction using synchrotron radiation allows a diffraction signal to be obtained which corresponds only to the chemical phases containing a specific type of atom. Two diffraction diagrams are collected at two energies far from and close to the absorption edge in order to vary the 
imaginary part of the scattering factor for the specific type of atom. Anomalous X-ray diffraction measurements were carried out at the $\mathrm{H} 10$ beamline at the $1.85 \mathrm{GeV}$ DCI storage ring of the LURE facility at Orsay (France). This beamline [17] was devoted to the investigation of poorly crystallized materials by combining X-ray absorption spectroscopy (XAS) and X-ray diffraction (XRD) in the 4-20 keV energy range. The photon source was a bending magnet on the DCI storage ring. The intensity of the positron beam was about $300 \mathrm{~mA}$ during data collection.

\subsubsection{In-situ Analysis of Structure and Catalytic Activity}

The samples were treated in an Anton Paar XRK reaction chamber. The powdered sample $(0.2 \mathrm{~g})$ was placed on a ceramic porous holder and pressed lightly. The inlet reactant flow passed through the sample. For all in-situ XRD studies of reduction and carbide formation, gas pressure was 1 bar and flow rate was $1 \mathrm{~L} / \mathrm{h}$. In order to follow the structural modifications during reduction, samples were analysed in a stream of pure hydrogen with a temperature ramp of $5^{\circ} \mathrm{C} / \mathrm{min}$ and isothermal periods of $2.5 \mathrm{~h}$ during data acquisition. We have previously reported cobalt carbide formation under Fischer-Tropsch reaction conditions [18] during in-situ treatments of several hundreds of hours. In the present study, in order to accelerate carbide formation, the reduced catalysts were treated in the XRK reaction chamber under pure $\mathrm{CO}$ at $230^{\circ} \mathrm{C}$ for $15 \mathrm{~h}$. After carbide formation was confirmed (see below), the metallic cobalt phase was regenerated under pure hydrogen at $230^{\circ} \mathrm{C}$.

The gas handling system of the reaction chamber has been modified so as to be able to carry out analysis under realistic Fischer-Tropsch conditions. The reaction conditions have been chosen in order to avoid heavy wax formation:
$T=230^{\circ} \mathrm{C}, P=3 \mathrm{bar}, \mathrm{H}_{2} / \mathrm{CO}=9, \mathrm{~W} / \mathrm{F} \approx 8.4 \times 10^{-2} \mathrm{~g} \cdot \mathrm{h} \cdot \mathrm{L}^{-1}$. Products were analysed at the exit by on-line gas chromatography and the heaviest products were condensed after the cell for off-line analysis. The activity was followed via $\mathrm{CO}$ consumption.

\subsection{Modelling Wide Angle X-Ray Scattering}

Simulation of XRD diagrams allows the influence of stacking faults on the diffracted intensity to be studied. Two approaches to XRD simulation are considered here, an atomistic model of particles in which stacking faults are explicitly included, and statistical modelling which allows some quantitative information to be obtained on the stacking fault probability. In both cases, any contribution from the support is not included in the simulation.

\subsubsection{Atomistic Simulation of Cobalt Clusters}

A simple way to calculate the diffraction diagram of the metallic part of a catalyst composed of a collection of nanometer scale metallic clusters with known geometry but random orientation and position is to use the Debye scattering Equation 1. This type of simulation has recently been applied successfully to the determination of stacking fault densities in gold nanoclusters [19].

$$
I(q)=\Sigma_{i} \Sigma_{j} f_{i}(q) f_{j}(q) \sin \left(q R_{i j}\right) / q R_{i j}
$$

In this equation, $I(q)$ is the angle dependent intensity from coherent scattering, $q$ bisects the angle between the incident and scattered directions, which in turn define the scattering plane. The sums over $i$ and $j$ are over all the atoms, $R_{i j}$ being the distance between the atom $i$ and $j$ and $f_{i}$ and $f_{j}$ being the

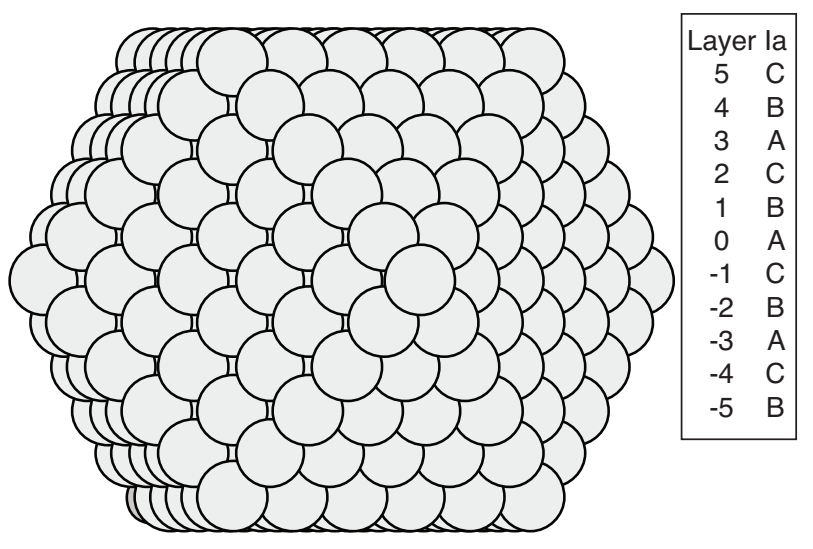

Figure 1

Representation of a cubooctahedral cluster containing 561 atoms and an fcc stacking of atomic layers.

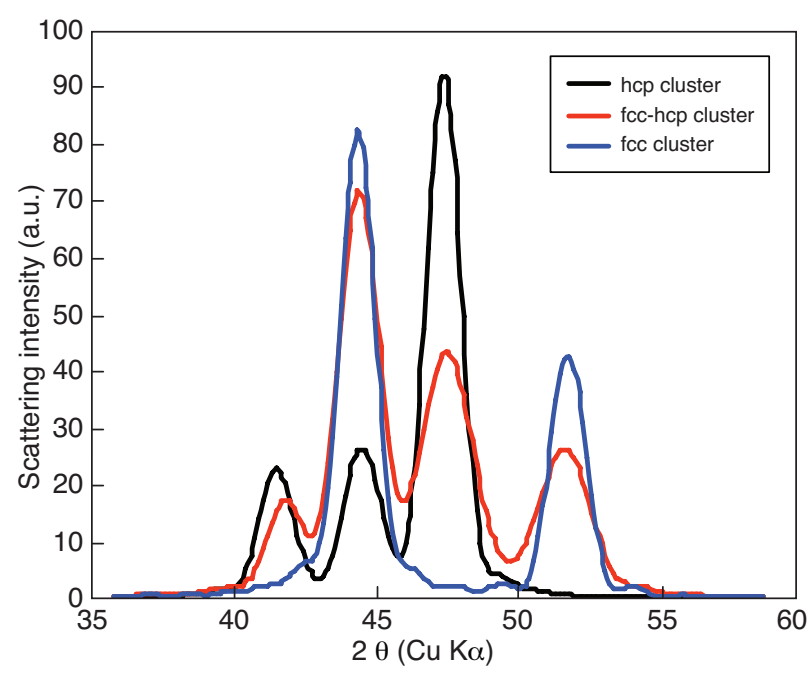

Figure 2

Calculated scattering intensities of clusters with different stacking sequences. 
angle dependent atomic scattering factors, taken from reference [20].

To illustrate the stacking sequence, Figure 1 represents a small $(3 \mathrm{~nm})$ cubooctahedral fcc cluster, containing 561 atoms.

In the simulations shown in Figure 2 and the following sections, diffraction intensities were calculated for much larger (7 nm diameter) clusters, containing 36 atomic layers (17900 atoms). Starting from an fcc cluster, stacking faults were progressively introduced in the particle simulation and the atomic coordinates recalculated. At the end of this structural modification, a hcp cluster is obtained. In the calculated diffraction diagrams of the end-members of this series the Bragg diffraction peaks of an fcc or a hcp structure are clearly visible. We have also calculated the diffraction diagram for a fcc-hcp cluster which is fcc in the upper part (positive numbered layers) and hcp in the lower part (negative numbered layers). The diffraction diagram of this case presenting two virtually independent fcc and hep structures also displays the two sets of diffraction peaks, as would also be expected for a mixture of particles, each presenting one or other of the structures.

\subsubsection{Statistical Simulation}

The DIFFAX software [21] allows calculation of the diffracted intensity from an infinite crystal containing stacking faults. Independent probabilities are defined for transitions from an fcc structure to a hcp structure and for the reverse transition. An example is given in Figure 3 for an fcc structure with increasing probabilities of fcc to hcp transition. One obvious effect is to decrease the diffracted intensity at the fcc peak positions and increase the hcp contribution. The introduction of stacking faults clearly also leads to a diffracted intensity distribution different from that of a superposition of fcc and hcp structures. Of particular note here is the appearance of diffracted intensity at positions intermediate between those of the pure fcc or hcp structures. In addition, peak broadening is predicted, due to the introduction of a finite thickness of the coherent domains. This latter effect renders the calculation of the "real" particle size difficult in the presence of stacking faults.

\section{EXPERIMENTAL RESULTS}

\subsection{Temperature Programmed Reduction of Supported Catalysts}

TRP profiles are shown in Figure 4 for $\mathrm{Co} / \mathrm{SiO}_{2}, \mathrm{Co}-\mathrm{Ru} / \mathrm{SiO}_{2}$ and $\mathrm{Co} / \mathrm{Al}_{2} \mathrm{O}_{3}$ catalysts.

For $\mathrm{Co} / \mathrm{TiO}_{2}$, a reduction profile intermediate between the silica and alumina samples was observed. The TPR profile of this solid is not shown as its reduction was not studied in detail, but its final reduced state is investigated below, using anomalous X-ray diffraction.

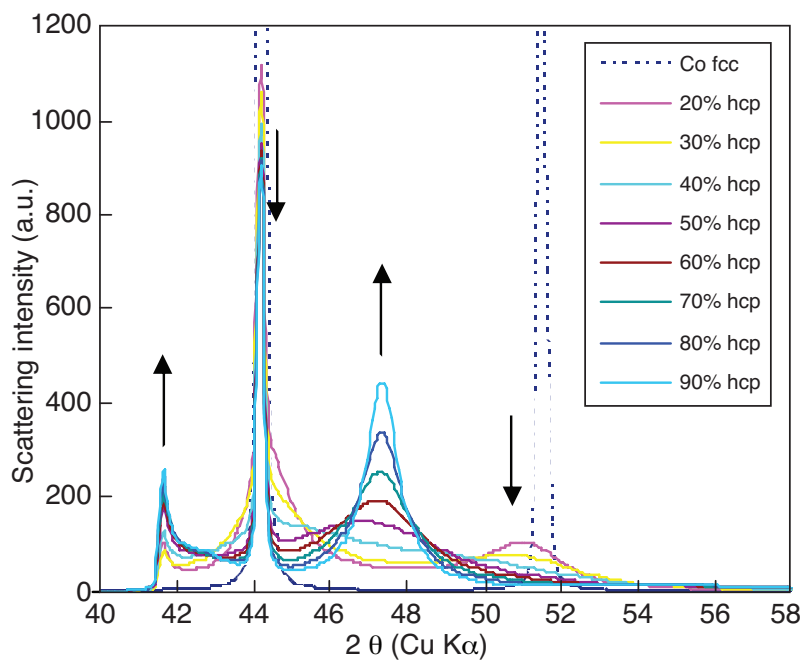

Figure 3

Calculated scattering intensities of clusters with different stacking fault probabilities Arrows are a guide to the eye, showing the increase or decrease of intensity due to an increasing probability of fcc to hcp transition.

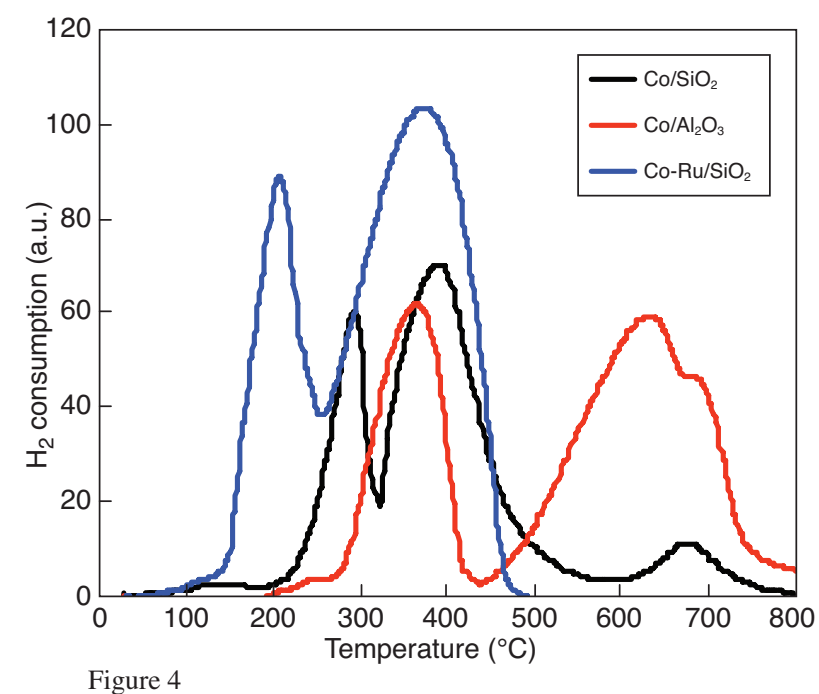

TPR analysis of the oxide catalysts.

Two major reduction peaks are observed for all samples. Although there is some uncertainty in the literature as to the attribution of these peaks, they are usually taken to be due to the reduction of $\mathrm{Co}_{3} \mathrm{O}_{4}$ to $\mathrm{CoO}$ (lower temperature peak) then to Co metal (higher temperature peak). High temperature reduction features are also observed (in the range 600 to $800^{\circ} \mathrm{C}$ ) which may be due to the formation of highly dispersed cobalt silicate or aluminate (see for example Ref. [22]) but it is not our intention in this work to discuss these phenomena in detail.

The key result for the purposes of further study of the cobalt structure is that $\mathrm{Co}-\mathrm{Ru} / \mathrm{SiO}_{2}$ reduces at a lower 
temperature than $\mathrm{Co} / \mathrm{SiO}_{2}$ whereas $\mathrm{Co} / \mathrm{Al}_{2} \mathrm{O}_{3}$ is reduced at a higher temperature. The first reduction maximum is observed at $200^{\circ} \mathrm{C}$ for $\mathrm{Co}-\mathrm{Ru} / \mathrm{SiO}_{2}, 290^{\circ} \mathrm{C}$ for $\mathrm{Co} / \mathrm{SiO}_{2}, 325^{\circ} \mathrm{C}$ for $\mathrm{Co} / \mathrm{TiO}_{2}$ and $380^{\circ} \mathrm{C}$ for $\mathrm{Co} / \mathrm{Al}_{2} \mathrm{O}_{3}$.

\subsection{Reduction of Bulk $\mathrm{Co}_{3} \mathrm{O}_{4}$ Followed by XRD}

Treatment of $\mathrm{Co}_{3} \mathrm{O}_{4}$ catalysts under hydrogen leads to reduction to $\mathrm{CoO}$ and then to consecutive reduction of the $\mathrm{CoO}$ to metallic cobalt, the reduction temperature depending somewhat on particle size [23]. For the bulk $\mathrm{Co}_{3} \mathrm{O}_{4}$ reference oxide, these events can be seen in Figure 5 starting respectively at approximately $250^{\circ} \mathrm{C}$ and $350^{\circ} \mathrm{C}$. The reduction results in the formation of two Co metal phases: a low temperature hexagonal close packed form (Co hcp) which is stable up to $450^{\circ} \mathrm{C}$ and a high temperature face centred cubic form (Co fcc) which begins to form after reduction above $500^{\circ} \mathrm{C}$.

Due to the large crystallite size of the bulk oxide, resulting in sharp diffraction peaks, the contributions of each phase can be clearly differentiated in Figure 5. For the small particle sizes found in catalysts, this will not be the case, in particular for the peaks at $44.2^{\circ} 2 \theta$ (Co fcc) and $44.3^{\circ} 2 \theta$ (Co hcp). Note however that the peaks at $41.4^{\circ} 2 \theta$ and $51.7^{\circ} 2 \theta$ attributed respectively to the Co hcp and the Co fcc structures are well separated from other contributions.

\subsection{Reduction of Supported Catalysts Followed by XRD}

In-situ X-ray diffraction analysis of the $\mathrm{Co} / \mathrm{SiO}_{2}$ catalyst (Fig. 6) clearly show the disappearance of the $\mathrm{CoO}$ phase under $\mathrm{H}_{2}$ when the reduction temperature increases from $300^{\circ} \mathrm{C}$ to $400^{\circ} \mathrm{C}$. When fully reduced, the formation of a complex Co metal phase, with a broad region of diffracted intensity between $2 \theta$ angles of $42^{\circ}$ to $54^{\circ}$, close to the positions of both fcc and hep peaks, is observed starting at a reduction temperature of $300^{\circ} \mathrm{C}$. In particular, a broad peak at $51^{\circ}$ to $52^{\circ} 2 \theta$ attributed to the Co fcc structure is visible even at low reduction temperatures relative to the bulk hcp to fcc transition. Although the silica support is amorphous, care must however be taken in interpreting the diffracted intensity, as the catalyst preparation itself may lead to the formation of mixed oxide phases that are not reduced under the conditions used here. This point will be considered in detail below.

XRD diagrams for the reduction of $\mathrm{Co}-\mathrm{Ru} / \mathrm{SiO}_{2}$ under hydrogen are shown in Figure 7. The form of the diagram observed for the reduction of $\mathrm{Co}-\mathrm{Ru} / \mathrm{SiO}_{2}$ (for which a low reduction temperature was observed by TPR) differs somewhat from that observed for the $\mathrm{Co} / \mathrm{SiO}_{2}$ catalyst (see Fig. 8), with a stronger intensity in the regions around the diffraction positions of the Co hcp structure (for instance at $41.4^{\circ} 2 \theta$ ). Again, precaution must be exercised in interpreting this diffracted intensity. The diagram nevertheless also points to a complex Co metal phase involving both hcp and fcc stacking.

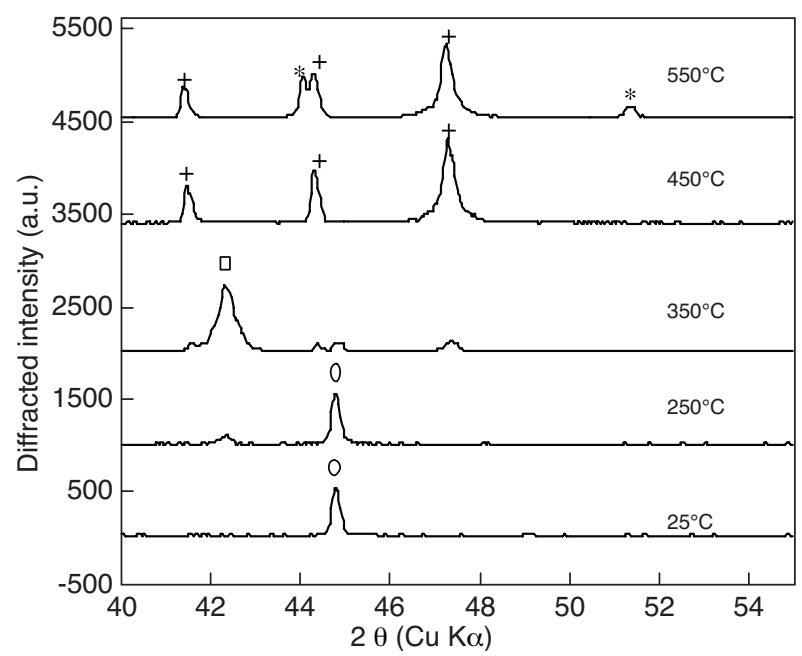

Figure 5

Reduction of bulk $\mathrm{Co}_{3} \mathrm{O}_{4}$ under hydrogen. Symbols represent expected diffraction peak positions $\left(\right.$ circles $=\mathrm{Co}_{3} \mathrm{O}_{4}$; squares $=\mathrm{CoO} ;$ plus signs $=$ hcp cobalt; asterisks $=$ fcc cobalt $)$.

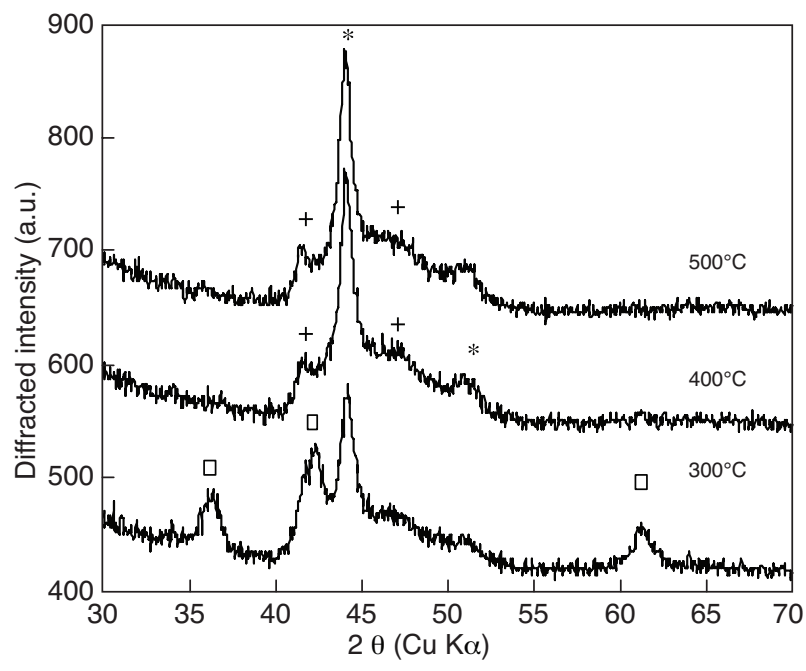

Figure 6

Reduction of $\mathrm{Co} / \mathrm{SiO}_{2}$ under hydrogen. Symbols represent expected diffraction peak positions (squares $=\mathrm{CoO}$; plus signs $=$ hcp cobalt asterisks $=$ fcc cobalt $)$.

For the $\mathrm{Co} / \mathrm{Al}_{2} \mathrm{O}_{3}$ catalyst (for which a high reduction temperature was observed by TPR), a significant contribution from $\mathrm{CoO}$ crystallites was still observed even after treatment with hydrogen at $500^{\circ} \mathrm{C}$ for several hours (Fig. 9). This is coherent with the TPR profile, showing only partial reduction of the cobalt at this temperature. Due to the $\mathrm{CoO}$ contribution, and to that of the alumina support, it is not possible to clearly identify the form of the diffraction pattern due to the cobalt particles. Extraction of the characteristic cobalt metallic component of the diffraction pattern is the subject of the following section. 


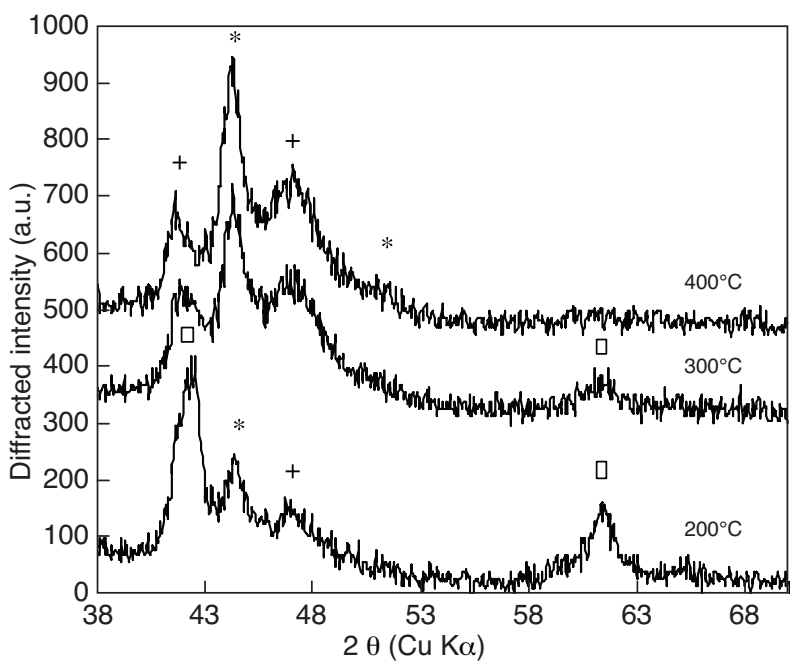

Figure 7

Reduction of $\mathrm{Co}-\mathrm{Ru} / \mathrm{SiO}_{2}$ under hydrogen. Symbols represent expected diffraction peak positions (squares $=\mathrm{CoO}$; plus signs $=$ hcp cobalt; asterisks $=$ fcc cobalt $)$.

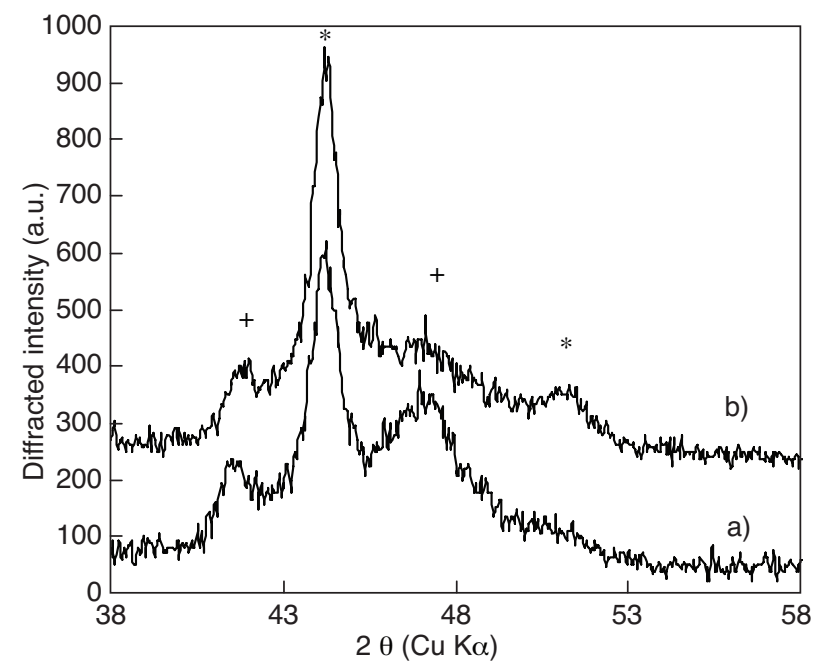

Figure 8

Comparison of reduced a) $\mathrm{Co} / \mathrm{SiO}_{2}$ and b) $\mathrm{Co}-\mathrm{Ru} / \mathrm{SiO}_{2}$. Symbols represent expected diffraction peak positions (plus signs $=$ hcp cobalt ; asterisks $=$ fcc cobalt $)$.

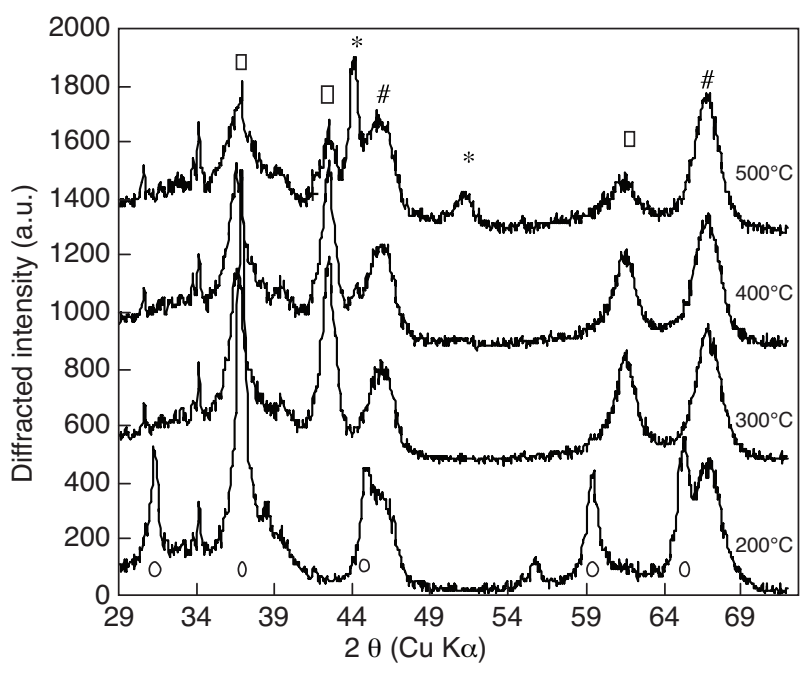

Figure 9

Reduction of $\mathrm{Co} / \mathrm{Al}_{2} \mathrm{O}_{3}$ under hydrogen. Symbols represent expected diffraction peak positions (circles $=\mathrm{Co}_{3} \mathrm{O}_{4}$; squares $=\mathrm{CoO}$; asterisks $=\mathrm{fcc}$ cobalt; hash symbol $(\#)=\mathrm{Al}_{2} \mathrm{O}_{3}$ support $)$.

\subsection{Extraction of the "Cobalt XRD" Contribution in Reduced Supported Catalysts}

\subsubsection{Subtraction of the Support Diagram}

A simple means to isolate the contribution to the diffraction pattern from catalyst particles is to subtract the XRD diagram due to the support alone. Some care is however required in normalisation, due to the difference in sample absorption, and artefacts may be introduced if the support is modified during the catalyst preparation. The effectiveness of this procedure is illustrated in Figure 10 by the case of the calcined $\mathrm{Co} / \mathrm{Al}_{2} \mathrm{O}_{3}$ catalyst. By subtracting, after appropriate normalisation, the diagram of $\mathrm{Al}_{2} \mathrm{O}_{3}$, the support contribution is removed leaving only diffraction peaks assigned to the $\mathrm{Co}_{3} \mathrm{O}_{4}$ structure.

The resulting diagrams obtained during reduction of the $\mathrm{Co} / \mathrm{Al}_{2} \mathrm{O}_{3}$ catalyst (Fig. 11) clearly show the persistence of the intermediate oxide $\mathrm{CoO}$ up to treatment temperature of $500^{\circ} \mathrm{C}$, followed by a complete reduction to metallic cobalt at $550^{\circ} \mathrm{C}$. For this catalyst, which shows a high reduction temperature in TPR characterisation, the hcp component is of low intensity, the structure being close to pure fcc.

The in-situ XRD experiments, performed under isothermal conditions at a given temperature, suggested that most of the cobalt is reduced at $550^{\circ} \mathrm{C}$, even though the dynamic TPR analysis clearly showed a high temperature reduction peak above $600^{\circ} \mathrm{C}$.

\subsubsection{Anomalous Diffraction}

Anomalous X-ray diffraction was used to confirm that the support is not modified during catalyst preparation, for example by the formation of an amorphous mixed oxide phase. Diagrams were recorded after in-situ reduction at energies of $10 \mathrm{eV}$ and $100 \mathrm{eV}$ below the Co $\mathrm{K}$ edge. As the data collection energies are different, the diagrams are represented as a function of $1 / d\left(\AA^{-1}\right)$. After normalisation, the difference between these two diagrams gives a signal coming only from chemical phases containing cobalt atoms (Fig. 12). The form 


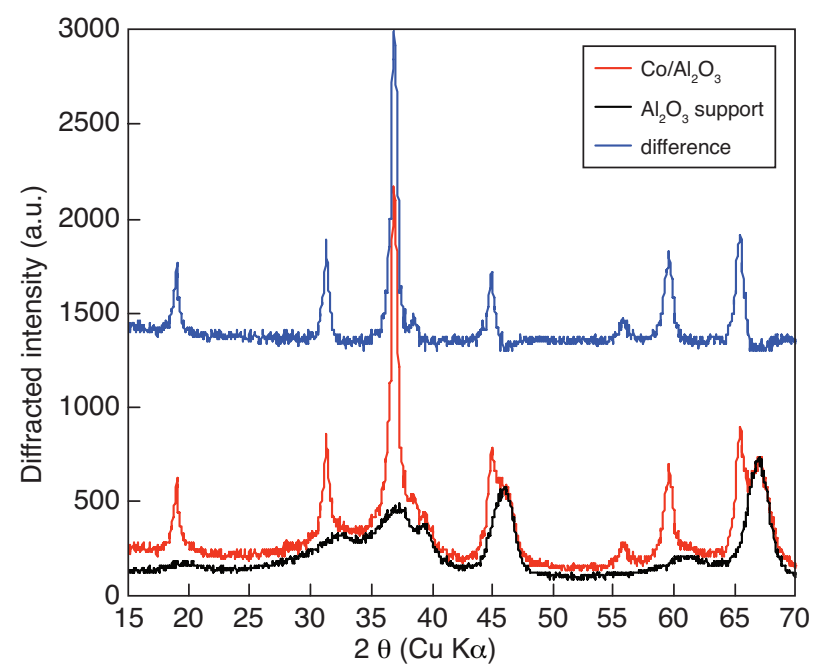

Figure 10

Diffraction patterns of $\mathrm{Co} / \mathrm{Al}_{2} \mathrm{O}_{3}, \mathrm{Al}_{2} \mathrm{O}_{3}$ and the difference pattern (offset for clarity).

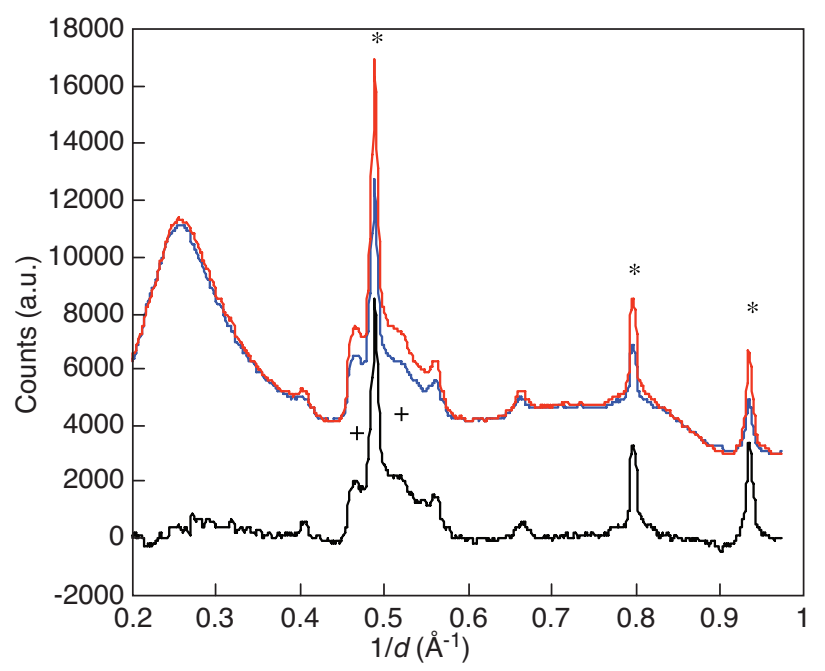

Figure 12

Diffraction patterns of the reduced $\mathrm{Co} / \mathrm{SiO}_{2}$ catalyst recorded $10 \mathrm{eV}$ (blue curve) and $100 \mathrm{eV}$ (red curve) below the Co K edge, and the difference pattern (black curve, rescaled for clarity). Symbols represent expected diffraction peak positions (plus signs $=$ hcp cobalt; asterisks $=$ fcc cobalt).

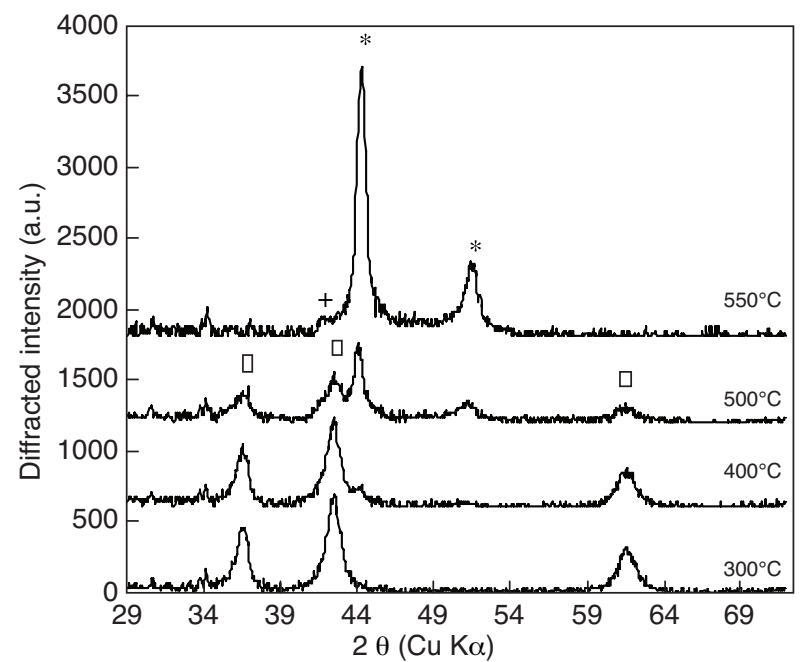

Figure 11

Reduction of $\mathrm{Co} / \mathrm{Al}_{2} \mathrm{O}_{3}$ under hydrogen with $\mathrm{Al}_{2} \mathrm{O}_{3}$ support contribution subtracted. Symbols represent expected diffraction peak positions (squares $=\mathrm{CoO}$; plus signs $=$ hcp cobalt; asterisks $=$ fcc cobalt $)$.

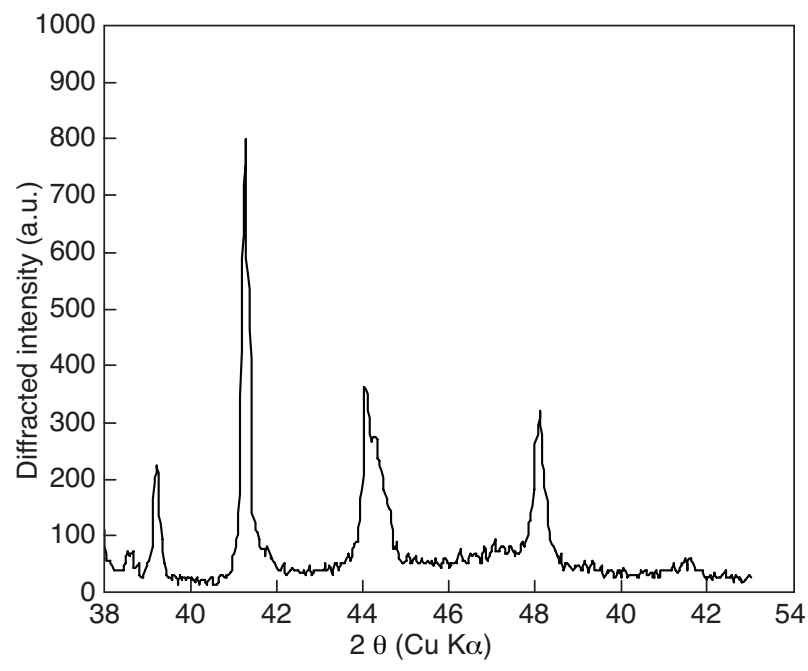

Figure 13

Diffraction pattern of the reduced $\mathrm{Co} / \mathrm{TiO}_{2}$ catalyst. Co peaks are obscured by the support diffraction pattern. of the diffracted intensities in these difference anomalous XRD patterns are similar to those observed in the laboratory XRD analysis (we illustrate here the case of $\mathrm{Co} / \mathrm{SiO}_{2}$ ). In particular, the broad feature in the range 0.45 to $0.6 \AA^{-1}$ (corresponding to $\mathrm{Cu} \mathrm{K \alpha}$ diffraction angles of $42^{\circ}$ to $54^{\circ} 2 \theta$ ) is observed, with a form for the diffracted intensity close to that reported above. No cobalt containing phases other than metallic cobalt are detected in the difference diagram.
Although the case of $\mathrm{Co} / \mathrm{TiO}_{2}$ is not discussed here in detail, the analysis of this catalyst (the conventional XRD pattern is shown in Fig. 13 and the anomalous XRD pattern in Fig. 14) shows that the use of anomalous diffraction allows extraction even of weak signals concealed by strong support diffraction peaks.

Despite increased noise in this pattern (resulting from the strong diffraction intensity and X-ray absorption of the 


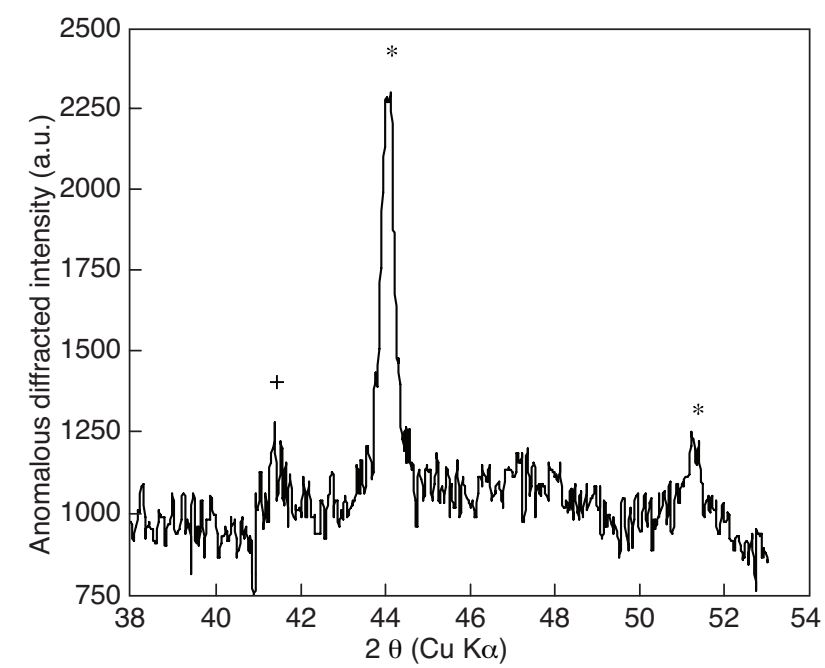

Figure 14

Anomalous diffraction pattern of the reduced $\mathrm{Co} / \mathrm{TiO}_{2}$ catalyst. Symbols represent expected diffraction peak positions (plus signs $=$ hcp cobalt; asterisks $=$ fcc cobalt $)$.

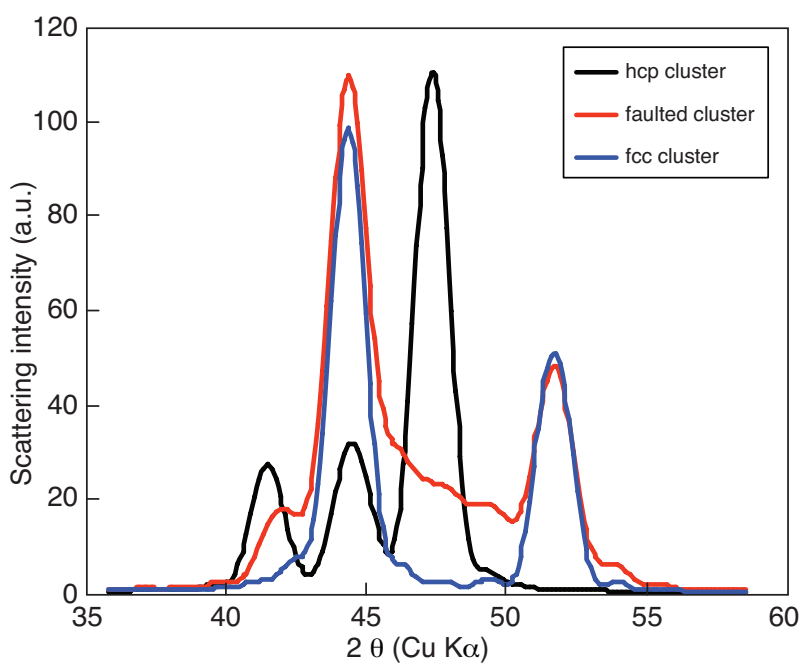

Figure 15

Calculated scattering intensity of a cluster with stacking faults (red curve, see text for details) compared with hcp (black curve) and fcc (blue curve) stacking. support), a strong contribution is observed in the regions corresponding to fcc peaks, compatible with the observed relatively high reduction temperature for this catalyst (intermediate between $\mathrm{Co} / \mathrm{SiO}_{2}$ and $\mathrm{Co} / \mathrm{Al}_{2} \mathrm{O}_{3}$ ).

\subsection{Modelling the "Cobalt XRD" Diagram}

\subsubsection{Atomistic Simulation}

An example of a defect structure, representing the incursion of two stacking faults near the centre (layers 2 and 5 in the above Fig. 1) of an fcc particle is given in Figure 15. Here, a complex diffraction pattern is observed, with intensity at diffraction positions intermediate between those due to the fcc or hcp structures.

The diagram simulated with stacking fault defects contained inside the particle clearly corresponds more closely to the experimentally observed diagrams than that calculated for independent fcc and hep contributions. We take this to be an indication that the metallic phase of the supported catalysts is not a mixture of particles that are either fcc or hcp, but rather consists of particles containing several stacking faults. One advantage of this direct simulation approach is that the «real» particle size is taken explicitly into account. For the particle size chosen for these simulations, the width of the features in the calculated diffraction pattern corresponds well to that observed in the experimental $\mathrm{Co} / \mathrm{SiO}_{2}$ diagram. The computation time required to calculate diagrams for a large number of structures unfortunately prevents further optimising the number and position of the stacking faults, which would be necessary to obtain a quantitative agreement between simulated and observed diagrams.

\subsubsection{Statistical Simulation}

A large number of configurations for stacking fault densities can be rapidly explored using the DIFFAX software. For the $\mathrm{Co} / \mathrm{SiO}_{2}$ catalyst, a simulated diagram corresponding closely to the observed pattern was obtained (Fig. 16) by choosing a probability of $40 \%$ that a plane of fcc stacking is followed by hcp stacking and a probability of $10 \%$ that a plane of hcp stacking is followed by fcc stacking.

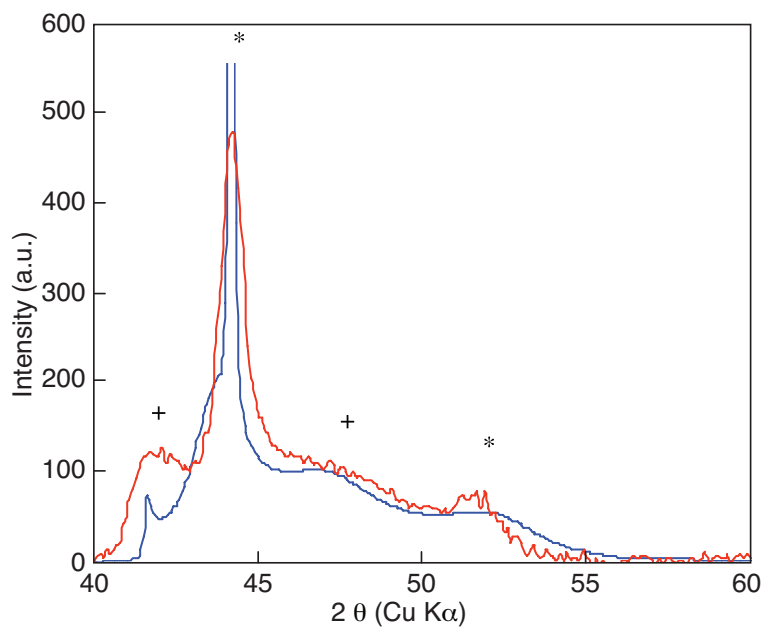

Figure 16

Comparison of the anomalous diffraction pattern of the reduced $\mathrm{Co} / \mathrm{SiO}_{2}$ catalyst and the simulated pattern for defect probabilities of $40 \% \mathrm{fcc} \rightarrow$ hcp stacking and $10 \%$ hcp $\rightarrow$ fcc stacking. Symbols represent expected diffraction peak positions (plus signs $=$ hcp cobalt; asterisks $=$ fcc cobalt). 
Here (contrary to the atomistic simulation) the features in the calculated pattern are somewhat sharper than in the experimental diagram. This is because, in the DIFFAX simulation, line broadening is uniquely due to the presence of stacking faults. Particle size effects are not taken into account. Convoluting the simulation with an appropriate smoothing function could be used to imitate the particle size effect but has not been carried out here.

The substantial probability (40\%) of an fcc to hcp transition confirms that the particle structure is a complex succession of fcc and hcp stacking. Again, the simulation of XRD diagrams leads to the conclusion that the metallic phase of the supported catalysts is not a mixture of single phase particles, but rather is a defective structure, containing a high density of stacking faults.

\subsection{Effect of $\mathrm{CO}-\mathrm{H}_{2}$ Treatments on Cobalt Microstructure}

Treatment under pure $\mathrm{CO}$ at $230^{\circ} \mathrm{C}$ leads to the formation of the carbide phase $\mathrm{Co}_{2} \mathrm{C}$. The degree to which the metallic cobalt is transformed depends on the initial structure (Fig. 17): the low reduction temperature catalysts showing higher diffraction intensity in the region of the Co hcp structure show only carbide peaks after treatment, whereas for the high reduction temperature $\mathrm{Co} / \mathrm{Al}_{2} \mathrm{O}_{3}$ catalyst significant intensity corresponding to the $\mathrm{Co}$ fcc phase remains. The transformation of Co fcc phase to carbide thus appears to be more difficult.

Subsequent treatment of the catalysts under hydrogen at $230^{\circ} \mathrm{C}$ leads to decomposition of the carbide phase to the metal (shown in Fig. 18). It is remarkable that the crystalline phase resulting from this low temperature decomposition of the carbide is hexagonal close packed. For the $\mathrm{Co} / \mathrm{SiO}_{2}$ catalyst after carbide formation and decomposition the diffraction diagram is simplified compared to the original reduced catalyst, and the peak positions and intensities are consistent with the presence of only the Co hcp phase. The microstructure of the catalyst particles has thus been modified. For $\mathrm{Co} / \mathrm{Al}_{2} \mathrm{O}_{3}$ the $\mathrm{Co}$ fcc contribution which remained after the treatment under $\mathrm{CO}$ is still observed after decomposition of the carbide. Structural modification occurs also in this case however, as a major contribution in the region of the Co hcp peaks is observed, whereas the original reduced catalyst showed essentially fcc stacking.

\subsection{Effect of Structure on Fischer-Tropsch Activity}

In the above, promoted and unpromoted catalysts on different supports are compared. It is clear that low reduction temperatures lead preferentially to formation of the hcp structure whereas high reduction temperatures correspond to increased fcc contributions. It is our aim to explore a possible relationship between these variations in microstructure and changes in catalytic activity. However, although the nature of the metal - support interaction is not entirely elucidated, it is generally considered to have an effect on the catalytic activity. In addition, variation of particle size in the above examples cannot be excluded, size measurement by DRX analysis being difficult here due to the complexity of the diffraction pattern. Particle size is known to influence reduction temperature [22] which in turn may induce variations in

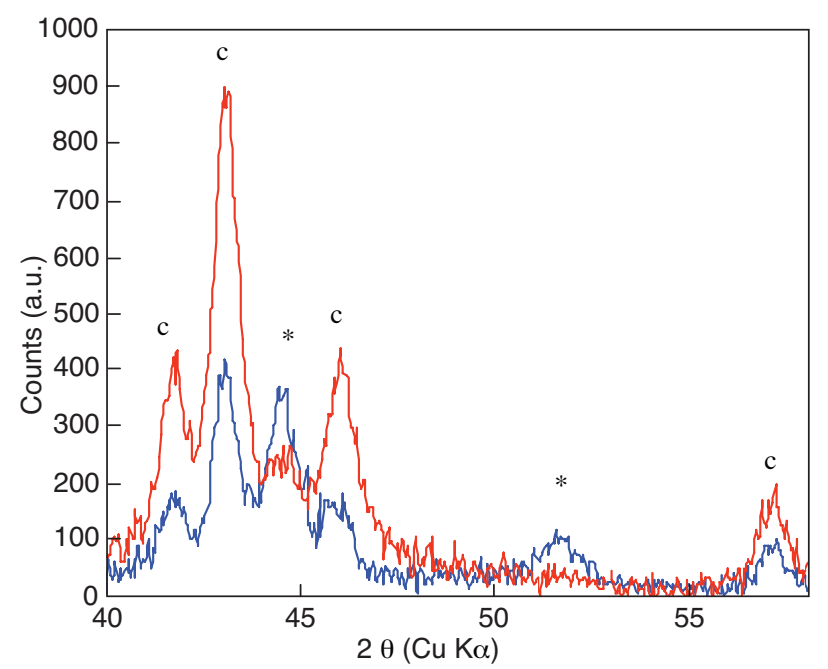

Figure 17

Diffraction patterns of catalysts reduced and treated for $15 \mathrm{~h}$ at $230^{\circ} \mathrm{C}$ under $\mathrm{CO}: \mathrm{Co} / \mathrm{SiO}_{2}$ (red curve) and $\mathrm{Co} / \mathrm{Al}_{2} \mathrm{O}_{3}$ (blue curve, alumina support subtracted). Symbols represent expected diffraction peak positions $(c=$ cobalt carbide; asterisks $=$ fcc cobalt $)$.

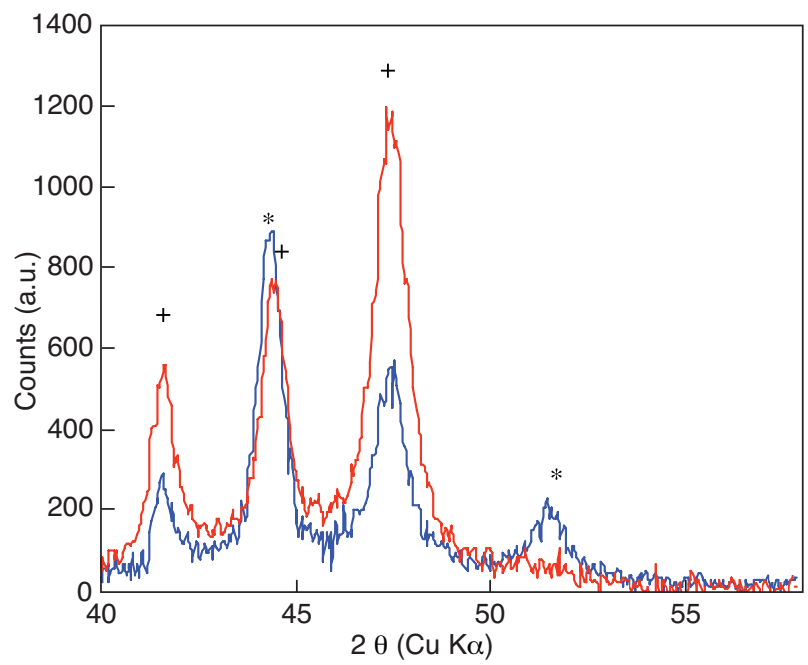

Figure 18

Diffraction patterns of catalysts reduced, carbided and rereduced at $230^{\circ} \mathrm{C}$ under hydrogen: $\mathrm{Co} / \mathrm{SiO}_{2}$ (red curve) and $\mathrm{Co} / \mathrm{Al}_{2} \mathrm{O}_{3}$ (blue curve, alumina support subtracted). Symbols represent expected diffraction peak positions (plus signs = hcp cobalt; asterisks $=$ fcc cobalt $)$. 


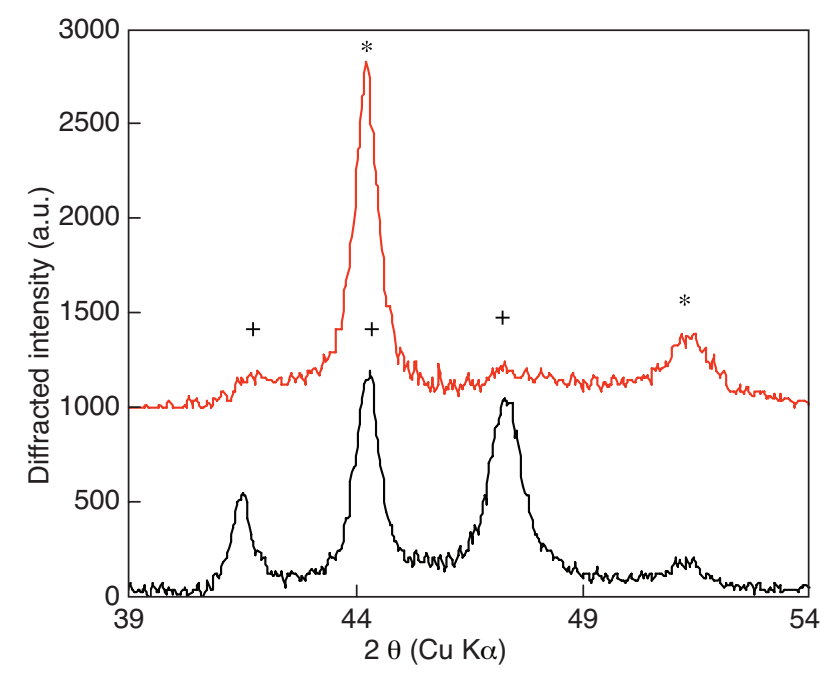

Figure 19

Diffraction patterns of the $\mathrm{Co} / \mathrm{Al}_{2} \mathrm{O}_{3}$ catalyst, with support diffraction pattern subtracted, after reduction (red curve, offset for clarity) and after carbide formation and decomposition (black curve). Symbols represent expected diffraction peak positions (plus signs $=$ hcp cobalt; asterisks $=$ fcc cobalt).

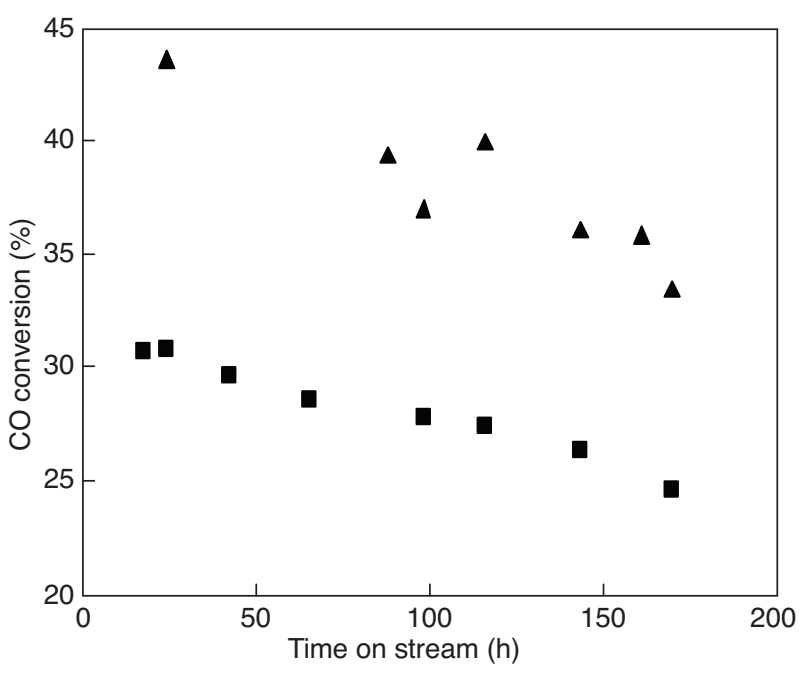

Figure 20

Activity of the $\mathrm{Co} / \mathrm{Al}_{2} \mathrm{O}_{3}$ catalyst, activated by reduction (fcc structure, squares) and by carbide formation and decomposition (hcp structure, triangles). microstructure. In order to study the effect of particle microstructure on activity, it is thus necessary to eliminate or limit the extent of these effects. The results of the previous sections enable us to develop a protocol to modify the microstructure of the metallic phase of Fischer-Tropsch catalysts without changing the support or degree of promotion.

Catalysts that have been treated successively under $\mathrm{CO}$ and hydrogen have a high proportion of Co hcp stacking, in contrast to the original reduced catalysts, where the type of stacking is a consequence of the reduction temperature and is thus indirectly dependant on the type of support or the presence of a promoter.

Figure 19 compares the XRD patterns for $\mathrm{Co} / \mathrm{Al}_{2} \mathrm{O}_{3}$ after reduction (the catalyst has essentially $\mathrm{Co}$ fcc structure with a small proportion of Co hcp stacking) and after carbide formation and decomposition (where the reverse is true).

The activity of the two catalysts was followed over several days in the modified Anton Parr XRD/reaction chamber via measurement of $\mathrm{CO}$ conversion under the conditions detailed above (Fig. 20). A slow deactivation of the catalysts was observed over the period, but the catalyst having mainly Co hcp stacking maintained a conversion rate $50 \%$ higher than the catalyst having mainly $\mathrm{Co}$ fcc stacking. Major products were identified by gas analysis as $\mathrm{C}_{1}$ (42\% of total products) $\mathrm{C}_{2}-\mathrm{C}_{4}(28 \%)$ and $\mathrm{C}_{5}+(29 \%)$ paraffin fractions, with no significant difference in selectivity between the two catalysts.

In order to compare meaningfully the activity of the catalysts, it is important to determine the dispersion, or accessible fraction of the cobalt atoms. The fraction of cobalt exposed to the surface is frequently determined from the particle size, measured using the width of the diffraction peaks. In our case, because of the presence of stacking faults, the peak width does not truly reflect the particle size, but rather the size of the coherent crystalline domains. The accessible cobalt fraction was thus determined by oxygen titration.

After reduction at $550^{\circ} \mathrm{C}$ (or after carbide decomposition at $550^{\circ} \mathrm{C}$ ), the catalyst samples were flushed in flowing $\mathrm{He}$ then the temperature was decreased to $20^{\circ} \mathrm{C}$. A series of pulses of oxygen in the He carrier gas were then passed through the catalyst bed, and the number of moles of oxygen consumed by the samples was calculated from the known pulse volume and the number of pulses reacting with the sample. The number of moles of cobalt reduced was calculated by assuming metal $\mathrm{Co}$ was converted to $\mathrm{Co}_{3} \mathrm{O}_{4}$. The ratio of this quantity to the total number of moles of cobalt (calculated from the sample mass and cobalt content) gives the accessible metallic cobalt fraction. Values for the accessible metallic cobalt fraction were $8.8( \pm 0.4) \%$, for the reduced catalyst and $9.6( \pm 0.4) \%$ for the catalyst after carbide formation and decomposition. Given the estimated experimental error of the oxygen titration measurements, the values for the accessible metallic cobalt fraction are close and do not allow the large difference in activity to be attributed to a change in dispersion.

A short catalytic test carried out just after a treatment under $\mathrm{CO}$ (formation of the carbide phase) confirmed, in agreement with the literature $[24,25]$, that the carbide is not highly active in Fischer-Tropsch synthesis.

Catalytic tests were also carried out on the $\mathrm{Co}-\mathrm{Ru} / \mathrm{SiO}_{2}$ catalyst. As the reduced catalyst in this case has a large proportion of Co hcp stacking, a novel treatment was necessary in order to increase the fcc content. From the arguments put 


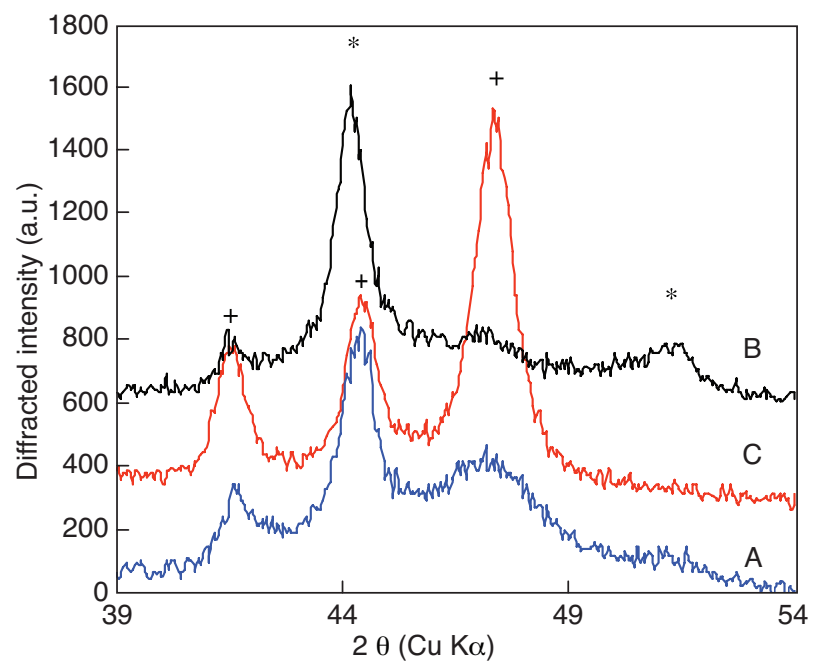

Figure 21

Diffraction patterns of the $\mathrm{Co}-\mathrm{Ru} / \mathrm{SiO}_{2}$ catalyst, activated by reduction (Test A: mixed fcc-hcp structure, blue curve), by high temperature inert gas treatment followed by direct high temperature reduction (Test B: fcc structure, black curve) and by carbide formation and decomposition (Test C: hcp structure, red curve). Symbols represent expected diffraction peak positions (plus signs $=$ hcp cobalt; asterisks $=$ fcc cobalt).

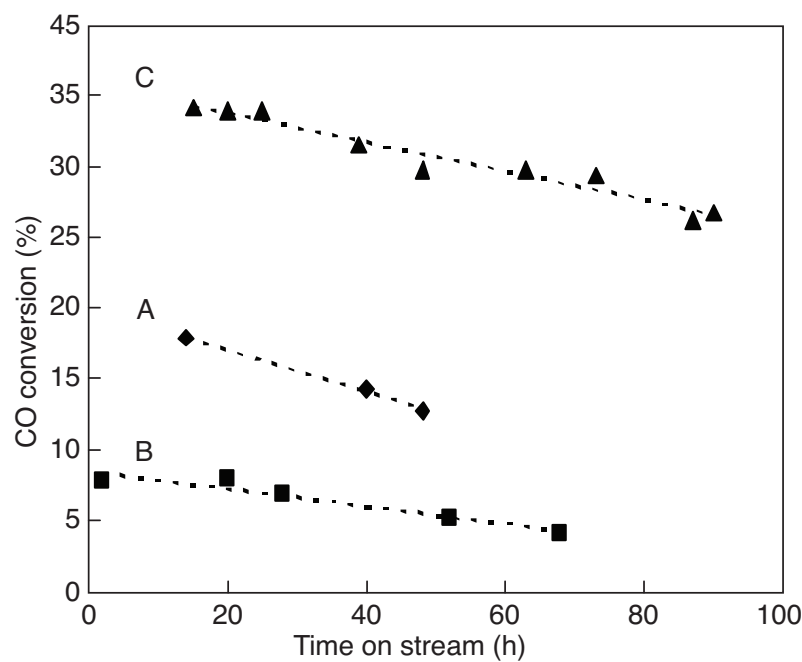

Figure 22

Activity of the $\mathrm{Co}-\mathrm{Ru} / \mathrm{SiO}_{2}$ catalyst, activated by reduction (Test A: mixed fcc-hcp structure, diamonds), by high temperature inert gas treatment followed by direct high temperature reduction (Test B: fcc structure, squares) and by carbide formation and decomposition (Test $\mathrm{C}$ : hcp structure, triangles). Dotted lines are a guide to the eye. forward in the preceding sections, a reduction at high temperature was considered necessary to achieve this. It was found that increasing the temperature under a flow of inert gas led to a partial reduction of the $\mathrm{Co}_{3} \mathrm{O}_{4}$ to $\mathrm{CoO}$, with no formation of a metallic phase up to $500^{\circ} \mathrm{C}$. By switching the flow of gas to pure hydrogen at this temperature, the catalyst was then reduced to form a phase giving an XRD diagram similar to the reduced $\mathrm{Co} / \mathrm{SiO}_{2}$ : i.e. with a significant proportion of Co fcc stacking. Although the effect of varying the treatment conditions under inert gas before reduction has not been studied in detail, it appears that a reduction at high temperature of the intermediate cubic oxide structure $\mathrm{CoO}$ does indeed lead preferentially to the formation of Co fcc stacking. $\mathrm{CO}$ conversion was then compared in three catalytic tests:

- test A: Co- $\mathrm{Ru} / \mathrm{SiO}_{2}$ catalyst reduced by increasing the temperature at $10^{\circ} \mathrm{C} / \mathrm{min}$ under hydrogen to $500^{\circ} \mathrm{C}$;

- test B: Co- $\mathrm{Ru} / \mathrm{SiO}_{2}$ catalyst enriched in Co fcc stacking as described above;

- test C: $\mathrm{Co}-\mathrm{Ru} / \mathrm{SiO}_{2}$ catalyst after reduction, carbide formation and decomposition.

XRD analysis at the start of each test is shown in Figure 21. While Test A investigates the activity of the complex defect phase described in preceding sections, Test B measures the impact of enhanced $\mathrm{Co}$ fcc stacking while Test $\mathrm{C}$ measures the impact of enhanced Co hcp stacking. The observed catalytic activities (Fig. 22) strikingly confirm the tests for $\mathrm{Co} / \mathrm{Al}_{2} \mathrm{O}_{3}$ : the higher the proportion of Co hcp stacking, the higher the $\mathrm{CO}$ conversion rate. Here, the activity of the catalyst most enriched in Co hcp stacking is three times that of the catalyst most enriched in Co fcc stacking. Again, a slow deactivation of these catalysts was observed over the test period.

\section{DISCUSSION}

We have shown by XRD diagram subtraction and confirmed by anomalous XRD that the broad diffraction intensity observed in reduced supported cobalt catalysts is due to the complex structure of the cobalt particles. Both atomistic simulation (calculation from the Debye equation) and statistical simulation (using DIFFAX software) confirm that this structure consists of a defect phase characterised by a high density of stacking faults. Each simulation method however has limitations in obtaining a quantitative description.

The hcp structure is the low temperature form of cobalt, as confirmed by the in-situ diffraction analysis of the reduction of the bulk oxide. The comparison of the $\mathrm{Co}-\mathrm{Ru} / \mathrm{SiO}_{2}$, $\mathrm{Co} / \mathrm{SiO}_{2}$, and $\mathrm{Co} / \mathrm{Al}_{2} \mathrm{O}_{3}$ catalysts shows a trend which is thus coherent with the temperatures at which the cobalt is seen by TPR to be reduced. The $\mathrm{Co}-\mathrm{Ru} / \mathrm{SiO}_{2}$ catalyst, which shows a first peak of cobalt reduction at $200^{\circ} \mathrm{C}$, has a higher diffracted intensity in the regions expected for the hcp structure compared with $\mathrm{Co} / \mathrm{SiO}_{2}$ (whose first reduction peak is at $290^{\circ} \mathrm{C}$ ). The $\mathrm{Co} / \mathrm{Al}_{2} \mathrm{O}_{3}$ catalyst, showing a first reduction peak at $380^{\circ} \mathrm{C}$, is essentially of fcc structure.

Further work would be needed to quantify the effect, but one would indeed expect that the probability of maintaining a hcp stacking would be higher if the structure is formed at 
lower temperature, whereas the probability of a transition to an fcc stacking would increase if the particles are formed at high temperature.

Preliminary results, suggesting that increasing the temperature under an inert gas followed by immediate reduction at high temperature under hydrogen leads to selective formation of the Co fcc phase, are also coherent with the proposition that the reduction temperature directly determines the microstructure of supported cobalt catalysts, whereas the effects of support and promoter are indirect consequences of this general rule.

Formation of the cobalt carbide phase followed by its decomposition to metallic cobalt has been shown here to lead to an increase in the proportion of hcp stacking. Structural data for the two cobalt phases (fcc and hcp) as well as for the carbide are given in Table 2. The structures of hexagonal (hcp) and cubic (fcc) cobalt contain identical planes in which the cobalt atoms are at a distance of $2.50 \AA$ from their six first neighbours. Only the stacking sequence is different, being $\mathrm{ABCABC}$ for cubic (fcc) cobalt and $\mathrm{ABAB}$ for hexagonal (hcp) cobalt. In the $\mathrm{Co}_{2} \mathrm{C}$ structure, the cobalt atoms of the 010 planes present the same hexagonal arrangement, with Co-Co distances slightly larger (2.654 ̊). The stacking sequence is $\mathrm{ABAB}$ (see Fig. 23).

We propose that, due to the similarities of cobalt carbide and hcp cobalt structures, the carbide transforms preferentially to the metallic cobalt structure which has the same ABAB stacking of the atomic planes. Thus, after decomposition of carbide under hydrogen, most of the metal formed is of hcp type.

It is possible the structure influences the diffusion of carbon into the metal. Carbon diffusion would be expected to be facilitated for the hcp stacking where a local carbide structure can be produced. This could explain the observation that the catalysts containing a large amount of hcp Co produce more carbide upon exposition to $\mathrm{CO}$ than those reduced at high temperature and mostly of fcc type.
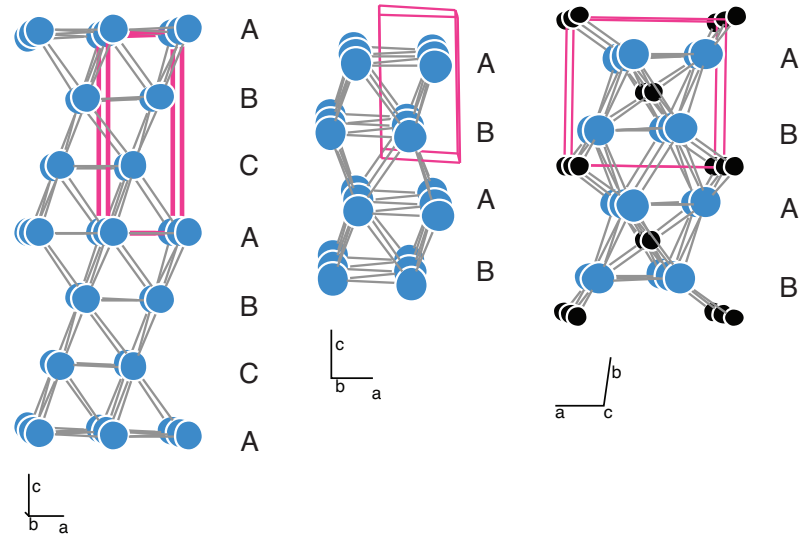

A

B

Figure 23

Structural representation of fcc Co (left), hcp Co (center) and $\mathrm{Co}_{2} \mathrm{C}$ (right).

The easier insertion of carbon into the hcp Co could also be at the origin of the higher activity of this structural type of cobalt in the Fischer-Tropsch reaction. Indeed, surface carbide or sorbed carbon issued from the dissociation of $\mathrm{CO}$ at the surface of the catalyst has been proposed as an intermediate in the formation of the hydrocarbon chains [26]. Difficult insertion of carbon in fcc cobalt phase would be in line with a lower activity observed for this structure.

\section{CONCLUSION}

In order to study in detail the structure of metallic catalyst particles, subtraction of an XRD diagram of the support alone is a simple and effective method for removing the diffraction signal due to the support, in cases where the support is not strongly crystallised and is not modified during the catalyst preparation. In our case, anomalous X-ray diffraction confirmed the validity of the approach.

TABLE 2

Structural data for fcc $\mathrm{Co}$, hcp Co, and $\mathrm{Co}_{2} \mathrm{C}$

\begin{tabular}{|c|c|c|c|c|c|}
\hline & & $\mathrm{fcc} C \mathrm{Co}$ & $\begin{array}{c}\mathrm{fcc} \mathrm{Co} \\
\text { in pseudo hexagonal cell }\end{array}$ & hcp Co & $\mathrm{Co}_{2} \mathrm{C}$ \\
\hline \multicolumn{2}{|c|}{ Space group } & Fm3m (225) & $\mathrm{P} 1$ & $\mathrm{P}_{3} / \mathrm{mmc}(194)$ & Pnnm (58) \\
\hline \multicolumn{2}{|c|}{ Cell parameters } & $\mathrm{a}=3.545 \AA$ & $\begin{array}{c}\mathrm{a}=2.507 \AA \\
\mathrm{c}=6.1401 \AA \\
\gamma=120^{\circ}\end{array}$ & $\begin{array}{c}\mathrm{a}=2.503 \AA \\
\mathrm{c}=4.061 \AA \\
\gamma=120^{\circ}\end{array}$ & $\begin{array}{l}\mathrm{a}=4.446 \AA \\
\mathrm{b}=4.371 \AA \\
\mathrm{c}=2.897 \AA\end{array}$ \\
\hline \multirow[t]{2}{*}{ Wyckoff } & Co & $1 \mathrm{a}$ & $4 \mathrm{~g}$ & $2 c$ & $4 \mathrm{~g}$ \\
\hline & $\mathrm{C}$ & - & - & - & $2 \mathrm{a}$ \\
\hline \multirow[t]{2}{*}{$x, y, z$} & Co & $\begin{array}{c}1 / 3,2 / 3,1 / 3 \\
2 / 3,1 / 3,2 / 3 \\
0,0,0 \\
\end{array}$ & $0,0,0$ & $1 / 3,2 / 3,1 / 4$ & $0.653,0.742,0$ \\
\hline & $\mathrm{C}$ & - & - & - & $0,0,0$ \\
\hline
\end{tabular}


The structure of supported metallic cobalt particles has been shown to be complex, consisting of a defect phase characterised by a high density of stacking faults. The degree to which defects are present has been shown to be related to the temperature at which the cobalt oxide is reduced to metallic cobalt. For low reduction temperatures the structure is close to hexagonal close packed, the stable phase at low temperature for bulk cobalt. Introduction of stacking faults leads to the presence of a significant amount of face centred cubic stacking in catalyst particles, even when the reduction of cobalt occurs at relatively low temperatures compared to the bulk metal transition temperature. High temperature reduction, whether induced by the nature of the support or by the reduction protocol, leads preferentially to fcc stacking.

Structural modification of the supported cobalt particles can be achieved via carbide formation under $\mathrm{CO}$ and its decomposition under hydrogen. The Co hcp structure has been shown to transform to carbide more easily than the Co fcc structure. More importantly, the decomposition of $\mathrm{Co}_{2} \mathrm{C}$ has been shown to lead to the selective formation of the Co hcp phase. As carbide decomposition takes place at relatively low temperatures, selective Co hcp formation is coherent with the observation that the temperature at which the metallic particles are formed directly determines the resulting microstructure.

Furthermore, observation of the $\mathrm{Co}_{2} \mathrm{C}$ structure shows that the cobalt atoms in the carbide are located on hexagonal planes similar to those of the metallic phases, and the stacking sequence is the same as in the Co hcp phase (ABAB), which could explain an easier path from one phase to the other.

Catalytic tests under representative Fischer-Tropsch conditions maintaining the same support, and promoter effects, with similar particle size, show that the presence of a majority of Co hcp stacking is beneficial to $\mathrm{CO}$ conversion, whereas increasing the proportion of Co fcc stacking has a prejudicial effect on catalyst activity.

Although cobalt carbide is not an active phase in FischerTropsch synthesis, we can speculate that the facile formation of carbide from the hcp structure and decomposition of the carbide to hcp cobalt may be at the origin of this effect, perhaps facilitating the insertion of carbon atoms (from $\mathrm{CO}$ decomposition) and their extraction (on hydrocarbon formation) in the surface layer of the working catalyst.

These results thus point to possible future study both to improve the understanding of the role of «surface carbon» in the mechanism of Fischer-Tropsch catalysis and for the development of more active catalysts.

\section{ACKNOWLEDGMENTS}

The authors are indebted to C. Verdon and P. Chaumette of IFP, and M. Gailhanou at LURE for help in the experimental work. Financial support was provided from the European "PARSEC" project CJ J0F3-CT95 0016 and the Chemistry Department of the CNRS.

\section{REFERENCES}

1 Dry M.E. (2002) The Fischer-Tropsch process: 1950-2000, Catal. Today 71, 227.

2 Khodakov A.Y., Chu W., Fongarland P. (2007) Advances in the development of novel cobalt Fischer-Tropsch catalysts for synthesis of long-chain hydrocarbons and clean fuels, Chem. Rev. 107, 1692-1744.

3 Storsæter S., Tøtdal B., Walmsley J.C., Tanem B.S., Holmen A. (2005) Characterization of alumina-, silica-, and titaniasupported cobalt Fischer-Tropsch catalysts, J. Catal. 236, 139.

4 Concepción P., López C., Martínez A., Puntes V.F. (2004) Characterization and catalytic properties of cobalt supported on delaminated ITQ-6 and ITQ-2 zeolites for the FischerTropsch synthesis reaction, J. Catal. 228, 321 .

5 Liu Y., Chen J., Fang K., Wang Y., Sun Y. (2007) A large pore-size mesoporous zirconia supported cobalt catalyst with good performance in Fischer-Tropsch synthesis, Catal. Commun. 8, 945.

6 Martínez A., López C., Márquez F., Díaz I. (2003) FischerTropsch synthesis of hydrocarbons over mesoporous Co/SBA-15 catalysts: the influence of metal loading, cobalt precursor, and promoters, J. Catal. 220, 486.

7 Kraum M., Baerns M. (1999) Fischer-Tropsch synthesis: the influence of various cobalt compounds applied in the preparation of supported cobalt catalysts on their performance, Appl. Catal. A-Gen. 186, 189.

8 Xu D., Li W., Duan H., Ge Q., Xu H. (2005) Reaction performance and characterization of $\mathrm{Co} / \mathrm{Al}_{2} \mathrm{O}_{3}$ Fischer-Tropsch catalysts promoted with Pt, Pd and Ru, Catal. Lett. 102, 229.

9 Zhang J., Chen J., Ren J., Sun Y. (2003) Chemical treatment of $\gamma-\mathrm{Al}_{2} \mathrm{O}_{3}$ and its influence on the properties of Co-based catalysts for Fischer-Tropsch synthesis, Appl. Catal. A-Gen. 243, 121.

10 Chernavskii P.A., Khodakov A.Y., Pankina G.V., Girardon J.-S., Quinet E. (2006) In situ characterization of the genesis of cobalt metal particles in silica- supported Fischer-Tropsch catalysts using Foner magnetic method, Appl. Catal. A-Gen. 306, 108-119.

11 de la Pena O'Shea V.A., Homs N., Fierro J.L.G., Ramirez de la Piscina P. (2006) Structural changes and activation treatment in a $\mathrm{Co} / \mathrm{SiO}_{2}$ catalyst for Fischer-Tropsch synthesis, Catal. Today 114, 422-427.

12 Elbashir N.O., Dutta P., Manivannan A., Seehra M.S., Roberts C.B. (2005) Impact of cobalt-based catalyst characteristics on the performance of conventional gas-phase and supercritical-phase Fischer-Tropsch synthesis, Appl. Catal. 285, 169-180.

13 Enache D., Rebours B., Roy-Auberger M., Revel R. (2002) In Situ XRD Study of the Influence of Thermal Treatment on the Characteristics and the Catalytic Properties of CobaltBased Fischer-Tropsch Catalysts, J. Catal. 205, 346-353.

14 Srinivasan R., De Angelis R.J., Reucroft P.J., Dhere A.G., Bentley J. (1989) Structural characterization of cobalt catalysts on a silica support, J. Catal. 116, 144-163.

15 Bezemer G.L., Radstake P.B., Koot V., van Dillen A.J., Geus J.W., de Jong K.P. (2006) Preparation of Fischer-Tropsch cobalt catalysts supported on carbon nanofibers and silica using homogeneous deposition - precipitation, J. Catal. 237, 291-302. 
16 Kala S., Mehta B.R. (2007) Size-dependent structural, optical and hydrogenation properties of $\operatorname{Pr}$ nanoparticle layers, J. Alloy. Compd. 431, 10-15.

17 Gailhanou M., Dubuisson J.M., Ribbens M., Roussier L.,Bétaille D., Créoff M., Lemonnier M., Denoyer J., Bouillot C., Jucha A., Lena A., Idir M., Bessière M., Thiaudière D., Hennet L., Landron C., Coutures J.P. (2001) H10: A materials and high temperature beamline at LURE/DCI, NIM $B$ 467-468, 745 .

18 Ducreux O., Lynch J., Rebours B., Roy M., Chaumette P. (1998) In situ characterisation of cobalt base Fischer-Tropsch catalysts: a new approach to the active phase, Stud. Surf. Sci. Catal. 119, 125-130.

19 Longo A., Martorana A. (2008) Distorted f.c.c. arrangement of gold nanoclusters: a model of spherical particles with microstrains and stacking faults, J. Appl. Cryst. 41, 446.

20 Sasaki S. (1983) KEK Report 83-82, Nat. Lab. for High Energy Physics, Tsukuba, Japan.

21 Treacy M.M.J., Newsam J.M., Deem M.W. (1991) A General Recursion Method for Calculating Diffracted Intensities from Crystals Containing Planar Faults, Proc. $R$. Soc. Lond. A 443, 499.
22 Khodakov A., Ducreux O., Lynch J., Rebours B., Chaumette P. (1999) Structural Modification of Cobalt Catalysts: Effect of Wetting Studied by X-Ray and Infrared Techniques, Oil Gas Sci.Technol. - Rev. IFP 54, 525-536.

23 Khodakov A., Lynch J., Bazin D., Rebours B., Zanier N., Moisson B., Chaumette P. (1997) Reducibility of Cobalt Species in Silica-Supported Fischer-Tropsch Catalysts, $J$. Catal. 168, 16.

24 Weller S., Hofer L.J.E., Anderson R.B. (1948) Role of Bulk Cobalt Carbide in the Fischer-Tropsch Synthesis, J. Am. Chem. Soc. 70, 799-801.

25 Jianmin X., Ding, Yunjie D., Tao W., Li Y., Weimiao C., Hejun Z., Yuan L. (2005) The formation of $\mathrm{Co}_{2} \mathrm{C}$ species in activated carbon supported cobalt-based catalysts and its impact on Fischer-Tropsch reaction, Catal. Lett. 102, 265-269.

26 For a review of the surface carbide mechanism see: van der Laan G., Beenackers A.A.C.M. (1999) Kinetics and Selectivity of the Fischer - Tropsch Synthesis: A Litterature Review, Catal.Rev. 41, 255.

Final manuscript received in April 2008 Published online in October 2008 